\title{
DOES KNOWLEDGE AND INCREASED AWARENESS AMONG OUR FEMALE POSTGRADUATE MEDICAL STUDENTS CONTRIBUTE TO IMPROVE THEIR HEMOGLOBIN LEVELS?
}

\author{
SANCY MARY SAM, PADMAJA UDAYKUMAR*
}

Department of Pharmacology, FR Muller Medical College, Mangalore, Karnataka, India. Email: padmajaudaykumar@gmail.com

Received: 27 May 2017, Revised and Accepted: 08 July 2017

\section{ABSTRACT}

Objective: Anemia is frequent among young women including medical students that remain unnoticed. This study was conducted to determine the prevalence of anemia in women postgraduate (PG) medics.

Methods: Hemoglobin ( $\mathrm{Hb}$ ) level of the participants was estimated and correlated with history.

Results: Eligible women PG medics ( $\mathrm{n}=100$ ) with a mean \pm standard deviation (SD) age of $25.92 \pm 1.5$ years and body mass index (BMI) of $21.51 \pm 2.97$ were enrolled. Of 44 anemic students, 32 had moderate anemia and 21 (47.73\%) belonged to the $3^{\text {rd }}$ year postgraduation. Only 16 students were underweight, eight in anemic and non-anemic group each. None had any history of occult bleeding. Twenty-four (24.0\%) students had taken antihelminthic treatment within 6 months before enrollment. Mean Hb levels were $11.54 \pm 1.21 \mathrm{~g} / \mathrm{dL}$. There was a statistically significant difference $(\mathrm{p}<0.05)$ between mean $\mathrm{Hb}$ level of the anemic students $(\mathrm{Hb}-10.35 \mathrm{~g} / \mathrm{dL})$ and the non-anemic individuals $(\mathrm{Hb} 12.49 \mathrm{~g} / \mathrm{dL})$. There was no statistical significant difference $(\mathrm{p}>0.05)$ in the occurrence of anemia among vegetarians (mean \pm SD Hb $11.21 \pm 1.11 \mathrm{~g} / \mathrm{dL}$ ) and non-vegetarians (mean \pm SD $\mathrm{Hb} 11.61 \pm 1.23 \mathrm{~g} / \mathrm{dL}$ ). There was no statistical significance ( $\mathrm{p}>0.05)$ in $\mathrm{Hb}$ level/anemia and BMI, dietary habits, duration, and heavy flow during menstruation between non-anemic and anemic students.

Conclusion: Anemia is still a concern in young women, and PG medical students are no exempt. Although none had severe form, anemia of moderate severity is prevalent among our PG students. Dietary habits did not influence or contribute to the maintenance of adequate Hb levels. Knowledge increased awareness and being self-sufficient did not contribute to maintain adequate Hb level.

Keywords: Anemia, Body mass index, Dietary habits, Menstruation, Women postgraduate students.

(c) 2017 The Authors. Published by Innovare Academic Sciences Pvt Ltd. This is an open access article under the CC BY license (http://creativecommons. org/licenses/by/4. 0/) DOI: http://dx.doi.org/10.22159/ajpcr.2017.v10i10.20264

\section{INTRODUCTION}

Anemia, a common associate of adolescence particularly in women due to physiological changes, continues even in adulthood. The increased demand during pregnancy and lactation, if not met, can result in anemia, and a well-known fact supported by many studies has made the physicians to shift their focus on this group. Identifying this silent nutritional deficiency in women of reproductive age is important not only for the uneventful pregnancy and healthy offspring but also for maintaining the health and well-being to maintain and improve the work efficiency and quality of life [1].

Supplements are provided during the growth period in children and early adolescence through a government-initiated project in schools, aims to tackle this condition in this age group. In spite of continuous efforts by the health-care providers and government initiatives in India, it is saddening that one in every two women still suffers from anemia [2]. According to the World Health Organization (WHO), the highest number of individuals affected by anemia is observed in nonpregnant women aged 15-49.99 years [3].

The most neglected is the non-pregnant women population in their third decade as they are not aware of their anemic status. Those who are away from their home, either for academic or career purpose, depend on other sources of food such as cafeteria, mess, and bear the brunt most. It is known the fact that medics due to their hectic work and academic schedule many times skip a meal or make poor nutritional choices. In spite of awareness of nutritional deficiency, significant percentage of this population has been reported to have nutritional anemia. There are reports about the anemic status among undergraduate women medics [4], while data are lacking regarding the same in postgraduate (PG) women medical students.
Although the diagnosis of anemia is simple, it goes unnoticed for a longtime due to its non-specific clinical signs and lack of testing even among medical students. As anemia is associated with a low work capacity, as well as lasting effects on learning and cognitive function, attention, behavior and growth, identification of the disease, and contributing factors are a first step toward its management. Hence, we conducted this study to determine the prevalence of anemia among our PG women medics.

\section{METHODS}

An observational, analytical study was conducted to determine the proportion of female medical students with anemia in a medical college from coastal South India, after obtaining the Institutional Ethics Committee's approval and written informed consent from the participants. Our primary objective was to estimate the extent of anemia in women PG medical students and the factors contributing to it.

Participants were female PG medical students belonging to first, second, and third year of postgraduation from our institution, who gave their written consent. We also excluded those with bleeding disorders, a history of hematological disorders (i.e., thalassemia trait, sickle cell trait, and malignant conditions), who underwent major surgery in the recent past, and those who were pregnant/lactating mothers.

We captured details of history and findings of general examination on a pre-determined and pretested proforma. The hemoglobin $\mathrm{Hb}$ estimation was performed by automated method and results interpreted as per the WHO criteria [5]. Anemia is established if the $\mathrm{Hb}$ is below the cutoff points as recommended by the WHO.

\section{Statistical analysis}

Data were captured using Microsoft Excel worksheets (2010) and analyzed. Results were expressed as frequency, percentage, range, 
mean, and standard deviation (SD); tables were used to depict the results. We used descriptive analysis, and Chi-square test was used for analysis.

\section{RESULTS}

We enrolled 100 women medical PG students aged 23-29 years with a mean \pm SD age of $25.92 \pm 1.5$ years and body mass index (BMI) of 21.51 \pm 2.97 . Of $44(44.0 \%)$ anemic students, $21(47.73 \%)$ belonged to the $3^{\text {rd }}$ year postgraduation. Only 16 students were underweight, eight in anemic and non-anemic group each (Table 1). None had any history of occult bleeding or abnormal bleeding tendency. Twenty-four $(24.0 \%)$ students had taken antihelminthic treatment within 6 months of enrollment.

Mean $\mathrm{Hb}$ levels of the study group were $11.54 \pm 1.21 \mathrm{~g} / \mathrm{dL}$ with a range of $9.5-14 \mathrm{~g} / \mathrm{dL}$ (Table 2 ). There was a statistically significant difference $(\mathrm{p}<0.05)$ between mean $\mathrm{Hb}$ level of the anemic students $(\mathrm{Hb}-10.35 \mathrm{~g} / \mathrm{dL})$ and non-anemic individuals $(\mathrm{Hb}-12.49 \mathrm{~g} / \mathrm{dL})$

\section{Dietary habits}

A questionnaire was used to gather information regarding the dietary habits of the female PGs that included, dietary habits (type of food and extra meal) and beverages. There were 19 (19.0\%) vegetarians, of whom 11 (57.9\%) were anemic. Remaining 81 were mainly nonvegetarians who consumed either fish, meat, or egg once a day. Only 33 (40.74\%) were anemic among non-vegetarians. There was no statistical significant difference $(\mathrm{p}>0.05)$ in the occurrence of anemia among vegetarians (mean $\pm \mathrm{SD} \mathrm{Hb}-11.21 \mathrm{~g} / \mathrm{dL} \pm 1.11$ ) and nonvegetarians $($ mean $\pm \mathrm{SD} \mathrm{Hb}-11.61 \mathrm{~g} / \mathrm{dL} \pm 1.23$ ).

Thirty-six (36.0\%) participants consumed extra meals between their three main meals. There were $17(17.0 \%)$ individuals who drank tea within one hour of a meal as a habit. Although eight (50.0\%) of them were anemic, there was no statistical significance $(p>0.05)$ in Hb level/ anemia in these groups (Table 3).

\section{Effect of menstruation on hemoglobin status}

There was no statistically significant difference $(p>0.05)$ in the duration of menstruation between non-anemic ( $4.12 \pm 0.82$ days) and anemic students ( $4.25 \pm 0.61$ days). Heavy flow was noted in 37 (37.0\%) subjects as reported to pass clots. There was no statistically significant association $(p>0.05)$ between anemia and heavy flow (Table 3$)$.

\section{DISCUSSION}

Anemia, humankind's oldest disease, caused by nutritional deficiency, still remains a global issue though causes and severity vary from developed to developing and underdeveloped countries. With the advent of time, many fatal diseases have been identified, yet anemia is a concern to the physicians particularly when occurs in women. Increased demands during adolescence due to physiological changes and during pregnancy and lactation make the young women more vulnerable. In addition, food faddism and avoidance of particular food group are common in young women which increase the risk of micronutrient deficiencies [6]. This is largely unnoticed condition in this age group. Although various studies have been done in young women, particularly, women medics, there are limited data regarding anemia in women PG medical students. We selected this population, as the medical awareness is high in this group and is self-sufficient to support them financially.

The prevalence of anemia in young women in Asia is estimated to be $33 \%$ [3]. Mittal et al. reported that anemia is common in adolescent girls, more frequent among younger group (71.15\%) compared to older (28.85\%). Girls from lower socioeconomic group (76.92\%) comprised greater proportion of those with anemia [7]. Prevalence among young college women is estimated to be $24.62-26.7 \%$ [8] in United Arab Emirates (UAE) [9] and 25.4\% in Sri Lanka [10]. In India, prevalence among young women is reported to be $56.0 \%$ [11]. Few studies have assessed the prevalence of anemia in young Indian women medics
Table 1: Prevalence of iron deficiency anemia, with physical parameters of the study subjects

\begin{tabular}{lll}
\hline \multirow{2}{*}{ Parameter } & $\mathbf{n}(\%)$ & \\
\cline { 2 - 3 } & Anemic & Non-anemic \\
\hline All students & $44(44)$ & $56(56)$ \\
Year & & \\
$1^{\text {st }}$ & $12(27.3)$ & $19(33.9)$ \\
$2^{\text {nd }}$ & $11(25)$ & $17(30.6)$ \\
$3^{\text {rd }}$ & $21(47.7)$ & $20(35.7)$ \\
BMI & $8(18.2)$ & $8(14.3)$ \\
Underweight $(<18.5)$ & $35(79.5)$ & $40(71.4)$ \\
Normal $(>18.5-24.9)$ & $1(2.3)$ & $8(14.3)$ \\
Overweight $(\geq 25-<30)$ & 0 & $0(0)$ \\
Obese $(\geq 30)$ & & \\
\hline
\end{tabular}

$\mathrm{N}=100$. Table shows distribution of anemia and physical characteristics. $3^{\text {rd }}$ year students were anemic in higher in proportion; none were obese. BMI: Body mass index

Table 2: Proportion of participants with the four sets of classification of anemia

\begin{tabular}{lll}
\hline & Hb $(\mathbf{g} / \mathbf{d L})$ & Frequency (\%) \\
\hline Non-anemic & $>12$ & $56(56)$ \\
Mild anemic & $11-11.99$ & $12(12)$ \\
Moderately anemic & $8-10.9$ & $32(32)$ \\
Severely anemic & $<7.99$ & $0(0)$ \\
Total & & $100(100)$ \\
\hline
\end{tabular}

$\mathrm{N}=100$. Classification of anemia based on the WHO classification. None were severely anemic. Hb: Hemoglobin

Table 3: Distribution of non-anemic and anemic subjects according to dietary habits

\begin{tabular}{|c|c|c|c|}
\hline \multirow[t]{2}{*}{ Parameter assessed } & \multicolumn{2}{|l|}{ n (\%) } & \multirow[t]{2}{*}{ p value } \\
\hline & Anemic & Non-anemic & \\
\hline \multirow{2}{*}{\multicolumn{4}{|c|}{$\begin{array}{l}\text { Number of meals } \\
\text { supplemented with meat, } \\
\text { fish, or egg per day }\end{array}$}} \\
\hline & & & \\
\hline Zero & $8(18.2)$ & $2(3.6)$ & \multirow[t]{4}{*}{0.010} \\
\hline One & $11(25)$ & $30(53.6)$ & \\
\hline Two & $16(36.4)$ & $14(25)$ & \\
\hline Three & $4(9.1)$ & $5(8.9)$ & \\
\hline \multicolumn{4}{|c|}{$\begin{array}{l}\text { Drinking tea within one hour } \\
\text { of a main meal }\end{array}$} \\
\hline Yes & $8(18.2)$ & $9(16.1)$ & \multirow[t]{2}{*}{0.780} \\
\hline No & $36(81.2)$ & $47(83.9)$ & \\
\hline \multicolumn{4}{|c|}{$\begin{array}{l}\text { Passage of clots in menstrual } \\
\text { blood }\end{array}$} \\
\hline Yes & $19(43.2)$ & $18(32.1)$ & \multirow[t]{2}{*}{0.256} \\
\hline No & $25(56.8)$ & $38(67.8)$ & \\
\hline \multicolumn{4}{|c|}{$\begin{array}{l}\text { Antihelminthic treatment } \\
\text { within the past year }\end{array}$} \\
\hline Yes & 7 (15.9) & $17(30.4)$ & \multirow[t]{2}{*}{0.093} \\
\hline No & $37(84.1)$ & $39(69.6)$ & \\
\hline \multicolumn{4}{|c|}{ Taking iron supplements } \\
\hline Yes & $8(18.2)$ & $4(7.1)$ & \multirow[t]{2}{*}{0.092} \\
\hline No & $36(81.8)$ & $52(92.9)$ & \\
\hline
\end{tabular}

$\mathrm{N}=100$. Factors affecting the nutritional status were analyzed, none had significant effect on the status of hemoglobin except number of meals supplemented with meat, fish, or egg per day

varying between $19.13 \%$ [12] and 47.37 [13]. Khan et al. [14] too reported a high rate of prevalence of anemia in undergraduate medics. We observed a higher prevalence of $44 \%$.

Pasupala et al. [15] in their study on south Indian medical students reported that Indian women have lower $\mathrm{Hb}$. The mean $\mathrm{Hb}$ value of 
our participants was $11.54 \mathrm{~g} / \mathrm{dL}$; it was $10.35 \mathrm{~g} / \mathrm{dL}$ among the anemic ${ }^{7}$. participants and $12.49 \mathrm{~g} / \mathrm{dL}$ among non-anemic participants. Debbarma et al. too observed the mean $\mathrm{Hb}$ levels (11.6 g\%) in female medics and $50.0 \%$ of female medics were anemic [4]. In medics from UAE, mean $\mathrm{Hb}$ was higher (12.83 \pm 1.49 ) [8]. Manjula et al. [12] noted a mean $\mathrm{Hb}$ of $12.74 \mathrm{~g} / \mathrm{dL}$; they reported higher Hb levels $(11.39 \mathrm{~g} / \mathrm{dL} \pm 0.63)$ in anemic students compared to our study. Surprisingly, in spite of having adequate medical knowledge, $81.8 \%$ of anemic students were not on iron supplements in our study.

Ayoub et al. reported mean $\mathrm{Hb}$ of $12.8 \mathrm{~g} / \mathrm{dL} \pm 1.49$ in female medics from Dubai [8]. Similar higher Hb concentration $(13.7 \mathrm{~g} / \mathrm{dL})$ was noted by Shams et al. [1] in Tehran, wherein anemic medical students had mean $11 \pm 0.9 \mathrm{~g} / \mathrm{dL}$ of $\mathrm{Hb}$ which was higher compared to our anemic study population which could be due to the average low Hb levels of Indian women [16].

We followed the WHO criteria [5] to classify anemia into mild, moderate, and severe anemia. None of the participants in our study had severe anemia. Other studies in women medics also have not reported severe anemia [11,14-15]. Except from Rumi et al. with one female medic with $\mathrm{Hb}<8.0 \mathrm{~g} \%$ [4]. Moderate anemia was most common among our study population $(32 \%)$ while mild anemia was less $(12 \%)$. Rumi et al. too report a higher rate of mild $(21.9 \%)$ and moderate $(26.6 \%)$ anemia in female medics [4]. In contrast, Chaturanga et al. [10] noted lesser prevalence of moderate $(17.5 \%)$ and mild anemia (7.9\%). Contrasting results have been reported from India too, with mild anemia being more common (83.33\%-7.0\%) in women undergraduate medics $[12,13]$. Khan et al. noted mild anemia in women undergraduates in $44 \%$ and moderate in $12 \%$ [14]. However, Karkar et al. from Vadodara reported almost equal occurrence of mild and moderate anemia (mild $=42.5 \%$ and moderate $=43.11 \%$ ) [16].

We did not find any significant correlation between BMI and anemia in our study population. Normal BMI was observed in $79.5 \%$ of anemic students and $71.4 \%$ of non-anemics. Only one student was overweight and was anemic compared to eight in non-anemic group. None of our PGs was obese, similar to the observation of Manjula et al. [12]. In their study, normal and overweight category occupied a major portion in normal $(18.5 \%)$ and anemic $(81.5 \%)$ women medics. Undernourished comprised of $21.6 \%$ in anemic group and $78.4 \%$ in non-anemic group. We did not find any positive association between BMI and anemia in our study population.

Meat products such as red meat, poultry, and fish represent excellent dietary sources of highly bioavailable heme iron. Low consumption of red meat, vegetables, fruits, and cereals has been reported to be associated with iron deficiency anemia [17]. It is not surprising that anemia was less frequent in those who consumed non-vegetarian diet. Similar reports from India have pointed out this finding [12-14].

Other food habits, which were considered in this study, including drinking tea after main meals and consumption, which has been reported in $26.92 \%$ of young girls [7], did not show a statistically significant association with anemia though $50 \%$ of those who drank tea after food within an hour of main meal were anemic. Tea is known to reduce iron absorption from the gut, failed to prove the same in our study. Similar observation was reported from a study in the Abdulaziz University [18].

Heavy menstrual blood loss is an important risk factor to develop iron deficiency anemia; however, in our study, there was no statistically significant relationship between anemia and the number of days, the participants have menstruated. None of our participants had menstrual flow $>4.5$ days which is well within the normalcy. We found heavy flow as observed in few participants did not contribute to anemia. These observations are similar to that from the study at University of Hail [19].

Shill et al. [20] have documented the positive association between heavy flow and anemia as a greater number of anemic subjects $(n=34)$

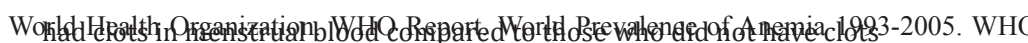

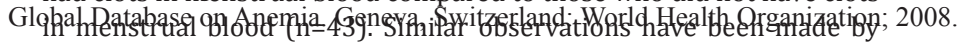

Al-Sayes et al. [19]. The research at the King Abdulaziz University too revealed that there was no significant relationship between anemia and clots in the menstrual blood [18].

Even our neighboring country has reported increased occurrence of anemia in women students. These authors have arrived at the possible causes in their study population as poor dietary habits, heavy menstrual bleeding, and lack of awareness [21].

Ours is the only study done in women PG medics, most of the studies are either on women students or specifically in undergraduate students or undergraduate women medics. Our study shows that despite awareness and self-sufficient to manage their nutritional needs, higher proportion of our PG students have anemia of moderate severity. We could not elicit a relation between the type of meal, dietary habits, and status of $\mathrm{Hb}$, though anemia was slightly less in non-vegetarians. However, we cannot derive a conclusion from our observation as the total sample size and that of vegetarians in our study is less. We did not assess the socioeconomic factors as we assumed that being PG medics, awareness regarding the nutritional deficiency is more in this group; for the same reason, residential status (hosteller or day scholar) was not recorded. We did not assess these anemic students clinically. As cognition and learning ability get affected by anemia, assessing these parameters would have been helped us to derive conclusion about the need and timing of medical intervention. We did not assess the effect of iron and other nutritional supplements in these patients.

Our study suggests that despite increased awareness through education, experience, and being self-sufficient, our future doctors do not take necessary measures to maintain an optimum $\mathrm{Hb}$ levels. We could not elicit any association between dietary habits, heavy menstrual bleeding, prior anthelminthic treatment, and anemia. Hectic work schedule, academic pressure might have made them to neglect their nutritional needs.

\section{CONCLUSION}

Anemia is still a concern in young women, and PG medical students are no exempt. Although none had severe form, anemia of moderate severity is prevalent among our PG students. Necessary measures need be taken to diagnose and treat, as dietary habits did not seem to influence or contribute significantly to the maintenance of adequate $\mathrm{Hb}$ levels.

\section{ACKNOWLEDGMENT}

Authors would like to thank all participants who consented to participate in this study. Authors acknowledge the Management of Fr Muller Medical College for their support during the conduct of the study. We appreciate the assistance of Dr Latha in editing and proof reading.

\section{REFERENCES}

1. Shams S, Asheri H, Kianmehr A, Ziaee V, Koochakzadeh L, Monajemzadeh M, et al. The prevalence of iron deficiency anaemia in female medical students in Tehran. Singapore Med J 2010;51(2):116-9.

2. Government of India. National Family Health Survey (NFHS) III (2005-06); India Report. Bombay: International Institute for Population Sciences; 2007.

3. World Health Organization. WHO Report. World Prevalence of Anemia 1993-2005. WHO Global Database on Anemia. Geneva, Switzerland: World Health Organization; 2008.

4. Debbarma R, Paul P, Debbarma B, Sutnga T, Loukrakpam B. Anaemia among medical students of regional institute of medical sciences (RIMS), Imphal Sch J Appl Med Sci 2016;4:3744-8.

5. WHO. Haemoglobin Concentrations for the Diagnosis of Anaemia and Assessment of Severity. Vitamin and Mineral Nutrition Information System, (WHO/NMH/NHD/MNM/11.1). Geneva: World Health Organization; 2011. Available from: http://www.who.int/vmnis/ indicators/haemoglobin.pdf. [Last accessed on 2016 Aug 30]. 
6. Fayet-Moore F, Petocz P, Samman S. Micronutrient status in female university students: Iron, zinc, copper, selenium, vitamin B12 and folate. Nutrients 2014;6(11):5103-16.

7. Bhanushali MM, Shirode AR, Joshi YM, Kadam VJ. An intervention on iron deficiency anemia and change in dietary behavior among adolescent girls. Int J Pharm Pharm Sci 2011;3:40-2.

8. Ayoub AI. Iron deficiency anemia in Dubai medical college for girls: A preliminary study. J Egypt Public Health Assoc 1995;70(1-2):213-28.

9. Sultan AH. Anemia among female college students attending the University of Sharjah, UAE: Prevalence and classification. J Egypt Public Health Assoc 2007;82(3-4):261-71.

10. Chathuranga G, Balasuriya T, Perera R. Anaemia among female undergraduates residing in the hostels of university of Sri Jayewardenepura, Sri Lanka. Anemia 2014;2014:526308.

11. Nutrition in India. National Family Health Survey (NFHS-3) India 2005-06. Available from: http://www.dhsprogram.com/pubs/pdf/ FRIND3/FRIND3-VollandVol2.pdf. [Last accessed on 2016 Aug 31].

12. Manjula VD, Parameshwari P, Pothen LK, Sobha A. Prevalence of anemia among female undergraduate students of government medical college Kottayam, Kerala. Int J Med Health Sci 2014;3(2):133-8.

13. Pandey S, Singh S. A cross sectional study of nutritional anemia among medical students in a medical college, at Bilaspur, Chhattisgarh. Natl J Med Res 2013;3:143-6.

14. Khan B, Sukshohale ND, Jawade P. Prevalence of anemia among undergraduate medical students of Central India. Glob J Res Anal 2015;5:13-4

15. Pasupula DK, Reddy PS. When is a South Indian really anemic? Indian J Clin Biochem 2014;29(4):479-84.

16. Karkar PD, Kotecha PV. Prevalence of anemia among students of Nursing School of Vadodara. Nurs J India 2004;95(11):257-8.

17. Al-Quaiz JM. Iron deficiency anemia. A study of risk factors. Saudi Med J 2001;22(6):490-6

18. Al-Sayes F, Gari M, Qusti S, Bagatian N, Abuzenadah A. Prevalence of iron deficiency anaemia among females at university stage. J Med Lab Diagn 2011;2:5-11.

19. Mohamed S, Sweilem S. Prevalence of anemia levels in a sample of university female students. Int J Sci Res 2014;3:805-9.

20. Shill KB, Karmakar P, Kibria MG, Sattar MM. Prevalence of irondeficiency anaemia among university students in Noakhali region, Bangladesh. J Health Popul Nutr 2014;32(1):103-10.

21. Bano R, Ahmad N, Sharma BC, Agarwal A. Nutritional anemia in the medical students. Indian Med Gaz 2012;1:16-8. 